\title{
Comentario de libro \\ Romero, M. \& E. Hauenstein. 2014. Arboles de Temuco. Ediciones Universidad Católica de Temuco. 180 pp.
}

\author{
Jonathan Urrutia \\ Laboratorio de Invasiones Biológicas, Facultad de Ciencias Forestales, Universidad de Concepción, Chile. \\ Email: jurrutiaestrada@gmail.com
}

Los paisajes urbanos representan actualmente el 2,8 \% de la superficie terrestre del planeta y albergan el $50 \%$ de la población mundial (Millennium Ecosystem Assessment 2005). Mientras que las ciudades continúan en expansión y la población urbana no detiene su crecimiento, los hábitats remanentes y la biodiversidad dentro de las ciudades alcanzarán en el futuro una importancia de gran proporción (Crane \& Kinzig 2005). Es por lo anterior que conocer parte de dicha biodiversidad permitirá desenvolverse en un entorno más amigable y dar mayor aprecio a este aspecto muchas veces subvalorado.

El libro publicado por la Universidad Católica de Temuco y de los autores Mario Romero y Enrique Hauenstein, viene a llenar un importante vacío en cuanto al conocimiento de los árboles urbanos de la capital regional de La Araucanía, ya que hasta el momento sólo se conocían los trabajos de Hauenstein \& Leiva (1987), Hauenstein et al. $(1988,1989)$ y Romero-Mieres et al. (2009). Dicha obra se presenta en un formato de $23 \times 15 \mathrm{~cm}$. con un total de 180 páginas e imágenes a color de muy buena resolución. El texto describe un total de 64 especies vegetales arbóreas, de las cuales 15 son gimnospermas, 45 corresponden a angiospermas dicotiledóneas y 4 son angiospermas monocotiledóneas. En la ficha de cada especie se presenta una detallada descripción que incluye nombre común, nombre científico, tabla fenológica, nombres comunes afines, significado del nombre científico, detalles morfológicos varios, datos de propagación e información respecto de donde poder apreciar in-situ cada especie en la ciudad de Temuco. El material fotográfico que se adjunta a la descripción de cada especie es de muy buena calidad y de gran apoyo para lograr la identificación de los ejemplares. En total son 6 imágenes por cada ficha descriptiva que hacen referencia a la fisonomía típica de cada árbol, sus hojas, flores, frutos, semillas y corteza. Además de todo lo anterior, se dedica un apartado al funcionamiento y/o uso del libro, se entrega un listado adicional de otras especies posibles de ver en la ciudad y un glosario de términos botánicos que facilita la comprensión lectora.

Este libro se constituye como un material adecuado no sólo para el estudio de la botánica, sino también para satisfacer la simple necesidad de conocimiento del lector común. En su interior se deja ver la prolijidad con la cual los autores han abordado cada especie, a través de un lenguaje sencillo y comprensible pero sin descuidar la compleja nomenclatura botánica fundamental en este tipo de obras. El esmero, profesionalismo y el manejo acabado de la temática tratada, se refleja en que los autores no han dejado fuera ningún aspecto clave para la identificación de las especies; y entregan además datos precisos y claros respecto de la ubicación de los árboles en la ciudad de Temuco.

Es de esperar que la presente obra sea de utilidad y encuentre buena acogida no sólo en la comunidad científica de nuestro país, sino también en la población temuquense y en los miles de turistas que visitan la ciudad, quienes quizás sin tener un conocimiento acabado de las especies tienen contacto frecuente con ellas y suelen encontrar dificultades para su identificación.

\section{Bibliografía}

Crane, P. \& A. Kinzig. 2005. Nature in the metropolis. Science 308: 1225-1225.

Hauenstein, E. \& L. Leiva. 1987. Los árboles y arbustos de las plazas de Temuco. I. Plaza Aníbal Pinto. El árbol nuestro amigo 3: 18-20.

Hauenstein, E., L. Leiva \& M. González. 1988. Los árboles y arbustos de las plazas de Temuco. II. Plazas Manuel Recabarren y Teodoro Schmidt. El árbol nuestro amigo 4: 43-46. 
Hauenstein, E., L. Leiva \& M. González. 1989. Los árboles y arbustos de las plazas de Temuco. III. Plazas Dagoberto Godoy y Dreves. El árbol nuestro amigo 5: 49-53.

Millennium Ecosystem Assessment. 2005. Urban systems: Current state and trends. Island Press, Washington, U.S.A.http://www.millenniumassessment.org

Romero-Mieres, M., S. Rebolledo \& P. Jaramillo. 2009. Árboles ornamentales de la ciudad de Temuco, Región de La Araucanía (IX), Chile. Chloris Chilensis 12. 